\title{
Mid-Term Patency in Radial Artery and Saphenous Vein After Coronary Artery Bypass Grafting in Asymptomatic Patients Using 128-Slice CT Coronary Angiography
}

\author{
Ali Sadeghpour ${ }^{1}$; Hamidreza Pouraliakbar ${ }^{1}$; Rasoul Azarfarin ${ }^{1}$; Alireza Alizadeh Ghavidel ${ }^{1}$; \\ Somayeh Zavareian ${ }^{2}$; Ali Amirahmadi ${ }^{1,}$

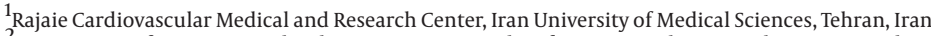 \\ ${ }^{2}$ Department of Operative and Esthetic Dentistry, Faculty of Dentistry, Islamic Azad University, Tehran, Iran \\ ${ }^{*}$ Corresponding author: Ali Amirahmadi, Rajaie Cardiovascular Medical and Research Center, Iran University of Medical Sciences, Tehran, IR Iran. Tel/Fax: +98-2188625679, E-mail: \\ amirahmadias@yahoo.com
}

Received: September 21, 2014; Revised: October 13, 2014; Accepted: October 19, 2014

\begin{abstract}
Background: Patency of the revascularization conduit is an essential predictor of long-standing survival after coronary artery bypass grafting.

Objectives: We have conducted this study to compare the mid-term patency rates of radial artery (RA), left internal thoracic artery (LITA) and also saphenous vein (SV) grafts in asymptomatic patients following coronary artery bypass graft surgery (CABG) undergoing total IV anesthesia.

Patients and Methods: In this study, 30 three-vessel disease patients with 104 RA, LITA, and SV grafts used concomitantly for primary isolated non-emergent CABG surgery were assessed. The primary end point was CT angiographic graft patency rate. After 53.5 (24-97) months' follow-up, graft patency was assessed using 128-slice CT coronary angiography. Logistic regression analysis was used to detect the independent predictors of graft failure.

Results: A total of 104 grafts, including 30 LITA, 44 SV, and 30 RA grafts, were studied. Cumulative graft patency rates were 93.3\% in LITA, 83.3\% in RA, and 70.5\% in SV grafts. Statistically significant difference was found between the LITA and the SV graft patency rates $(P=0.019)$, whereas the difference between the RA conduit patency and the LITA or SV graft patency rates did not have any statistical significance ( $\mathrm{P}=$ 0.424 and $P=0.273$, respectively). Independent predictors of RA grafts occlusion were native coronary stenosis $<70 \%$ and female gender. Conclusions: In our patients, the RA grafts had an acceptable patency rate in 2 to 5 years' follow-up. Although the SV grafts had a relatively higher patency rate than RA grafts in our asymptomatic patients, the patency rates in RAand SV grafts were close to each other. The RA graft function was poor in the patients with a higher number of risk factors and in the females.
\end{abstract}

Keywords:Coronary Artery Bypass Grafting; Saphenous Vein; Radial Artery; Vascular Graft Occlusion

\section{Background}

Patency of the revascularization conduit is an essential predictor of long-standing survival after Coronary artery bypass grafting (CABG) (1). The patency of the arterial grafts has been shown to be better comparing with venous grafts (1). The use of the left internal thoracic artery (LITA) grafted to the left anterior descending branch (LAD) of the left coronary artery has been established as the gold standard in CABG courtesy of its high patency in the mid- and long-term in comparison with the saphenous vein SV (2). Nonetheless, consensus has yet to emerge amongst experts as to what constitutes the second best conduit for CABG (3). The use of the SV as an aortocoronary conduit shows an acceptable short-term patency rate, which is similar to that of the use of the radial artery (RA) (4-6); however, its medium-term patency rate is liable to deteriorate, significantly (4). Several clinical reports support the use of RA conduits in preference to SV conduits (1, 4, 7-10), while there are other studies that suggest the opposite $(2,4,11)$. For example, Tranbaugh et al. (3) demonstrated favorable long-term (14 years) survival using the LITA, SV, and an RA conduit for CABG by comparison to using the LITA and SV. In contrast, Hortmann et al. (2) showed that the RA presented worse results than did the SV as a second graft in CABG, particularly in women who were grafted in the right coronary artery. Also, Fukui et al. (11) reported that the one year patency rate of the RA was significantly lower than that of the free right ITA and SV graft. Most controversies on the superiority or inferiority of the RA to the SV grafts arise from the selected patient populations (9-12), surgical techniques (off-pump vs. on-pump CABG) (13), and lengths of follow-up (early (< 1 year) and mid-term (1-5 years) or long-term (more than 5 years) (14).

Most studies conducted till now on graft patency rates 
recruited symptomatic patients $(2,12)$, drawing upon such different diagnostic modalities as coronary angiography $(1,12,15)$ and $\mathrm{CT}$ angiography (16).

\section{Objectives}

There is currently a dearth of data in the existing literature on the medium-term patency rates in the LITA, RA, and SV grafts after CABG in asymptomatic patients. Thus, the primary end point of the present study was to evaluate mid-term (two to five years) patency rates in the entire conduit grafts after $C A B G$ surgery in patients who remained asymptomatic using the noninvasive diagnostic tool, 128-slice, dual-source CT coronary angiography. The secondary end point was detecting the independent predictors of graft failure using the multivariate regression model.

\section{Patients and Methods}

\subsection{Patient Population}

The study proposal was approved by the hospital Ethics Committee, and written informed consent was filled out by all of the patients. In this study, 30 asymptomatic patients with class II-III of physical status according to American Society of Anesthesiologists (ASA) were randomly sampled from 200 patients who had formerly undergone elective CABG by a single attending surgeon between in the previous two to five years. All the patients had 3-vessel coronary artery stenosis and underwent multi-vessel surgical revascularization using the LITA, RA, and SV grafts. The symptomatic patients, diabetics and those who had concomitant valvular disease and patients who reject to undergoing $\mathrm{CT}$ angiography were excluded from the study. A total of 104 RA, LITA, and SV grafts used concomitantly for primary first-time elective CABG. During 53.5 (24-97) months' follow-up period, graft patency was evaluated by 128 -slice, dual-source CT coronary angiography. Logistic regression analysis was employed for the detection of the independent predictors of graft failure. The patients' demographic data and clinical parameters, including left ventricular ejection fraction (LVEF) and cardiovascular risk factors such as history of cigarette smoking, hyperlipidemia, and positive family history of coronary artery disease (CAD) and hypertension, were collected.

\subsection{Operative Procedure}

All the surgeries were performed by a single attending surgeon in the recent two to five years. Total IV anesthesia technique was applied using midazolam $(0.05-0.1 \mathrm{mg} /$ $\mathrm{kg})$, fentanyl $(\mathrm{l}, 25-40 \mu \mathrm{g} / \mathrm{kg})$ and cisatracurium $(0.2 \mathrm{mg} /$ $\mathrm{kg}$ ) for induction. Midazolam (0.05-0.1 mg/ $\mathrm{kg} /$ hour), fentanyl (0.1-0.2 $\mu \mathrm{g} / \mathrm{kg} /$ minute) and atracurium (0.3-0.6 mg/ $\mathrm{kg} /$ hour) were continuously infused for maintenance of anesthesia. The usual surgical techniques were used for the RA and SV harvesting and dissection of the LITA. Consequently, the dissection of the LITA was carried out in a pedicled manner and not skeletonized, the harvesting of the RA was made from the antecubital fossa to the wrist in the arm, and the SV harvesting was done in the standard method as a pedicled conduit with the vein branch included and also with ligation of its branches with metallic clips. All the graft conduits were created using cardiopulmonary bypass. All the distal anastomoses were made to all the coronary arteries with significant stenosis and acceptable run-off, and all the proximal anastomoses were sutured on the ascending aorta. There was no sequential or Y graft.

\subsection{Follow-up CT-Angiography}

All the patients underwent 128-slice, dual-source CT coronary angiography at a follow-up period of 53.5 (2497) months. All coronary CT-angiograms were obtained by one consultant radiologist. The primary end-point was to determine the proportions of the RA and SV grafts that were patent 53.5 (24-97) months after CABG. The graft was classified as either patent or totally occluded. Total occlusion was defined as the lack of visible opacification of the graft in the aortogram. Secondary CT-angiographic visual classification of the grafts was defined as follow: P1, ideal patency; P2, diminished flow states (narrowing in site of anastomoses or in the body of the graft) $50 \%$; P3, diminished flow states 50\%; P4, severe diffuse graft stenosis (string sign); and P5, complete occlusion.

\subsection{Statistical Methods}

All the results were analyzed using the statistical package SPSS 18.0 for Windows (SPSS Inc., Chicago, IL, USA). The numerical variables are demonstrated as mean $\pm S D$, and the categorical variables are presented by raw numbers (percentages). The continuous parameters were compared by independent samples t-test. The categorical parameters were compared by using the chi-square test (with Yates correction) or Fisher exact test, as necessary. The independent predictors of the RA graft failure were determined by using the logistic regression model. A $\mathrm{p}$ value $\leq 0.05$ was regarded statistically significant.

\section{Results}

Mean age of patients was $59.15 \pm 7.12$ (range 48-83) years. From the 30 patients entered into study a total of 104 grafts, consisting 30 (28.8\%) RA, 30 (28.8\%) LITA and 44 (42.4\%) SV were assessed. Collective graft patency rates were $28 / 30$ (93.3\%) in the LITA, $31 / 44$ (70.5\%) in the SV grafts and $25 / 30(83.3 \%)$ in the RA. Of these studied conduits, 78 (75\%) were grafted in male and $26(25 \%)$ were grafted in female patients. The mean follow-up (from CABG surgery to re-study by CT-angiography) was 4.46 (2 to 8) years.

There was a statistically significant difference between the LITA and SV graft patency rates (93.3\% vs. $70.5 \%$; P $=0.019$ ). However, there was no significant difference 
Sadeghpour A et al.

\begin{tabular}{|c|c|c|c|c|c|c|}
\hline & \multicolumn{3}{|c|}{ RA Grafts $(n=30)$} & \multicolumn{3}{|c|}{ SV Grafts $(n=44)$} \\
\hline & Patent & Occluded & P Value & Patent & Occluded & P Value \\
\hline Age, y & & & 1.000 & & & 0.302 \\
\hline$\geq 70$ & $2(8)$ & $0(0)$ & & $4(13)$ & $0(0)$ & \\
\hline$<70$ & $23(92)$ & $5(100)$ & & $27(87)$ & $13(100)$ & \\
\hline Gender & & & 0.011 & & & 0.237 \\
\hline Male & $21(84)$ & $1(20)$ & & $22(71)$ & $12(92)$ & \\
\hline Female & $4(16)$ & $4(80)$ & & $9(29)$ & $1(8)$ & \\
\hline LVEF, \% & & & 1.000 & & & 0.544 \\
\hline$\leq 30$ & $2(8)$ & $0(0)$ & & $3(10)$ & $0(0)$ & \\
\hline$>30$ & $23(92)$ & $5(100)$ & & $28(90)$ & $13(100)$ & \\
\hline RF, No. & & & 0.121 & & & 0.017 \\
\hline 0 & $7(28)$ & $1(20)$ & & $8(26)$ & $5(39)$ & \\
\hline 1 & $10(40)$ & $0(0)$ & & $7(23)$ & $7(54)$ & \\
\hline$\geq 2$ & $8(32)$ & $4(80)$ & & $16(51)$ & $1(7)$ & \\
\hline
\end{tabular}

Table 2. Independent Predictors of Radial Artery Graft Failure ${ }^{a}$

\begin{tabular}{lcc}
\hline Variable & PValue & OR (95\% CI) \\
\hline Age $\geq$ 70, y & 0.30 & $0.95(0.80-1.05)$ \\
Gender (female/male) & 0.04 & $2.56(1.50-11.30)$ \\
LVEF $\leq \mathbf{3 0}, \%$ & 0.20 & $1.06(0.95-1.18)$ \\
Risk factors, No. & 0.04 & $0.04(0.12-0.91)$ \\
\hline
\end{tabular}

${ }^{a}$ Abbreviations: LVEF, left ventricular ejection fraction; OR, Operating room

between the LITA and RA graft patency rates (93.3\% vs. 83.3\%; $\mathrm{P}=0.424)$ and between the SV and RA graft patency rates $(70.5 \%$ vs. $83.3 \%$; $\mathrm{P}=0.273)$. The patency rates of the RA and SV grafts were analyzed according to various clinical parameters, separately (Table 1$)$. The patency rate of the RA graft was lesser in women (4/8 (50\%)) than in men (21/22 (95\%)), ( $P=0.011)$ (Table 1$)$. There was no sex difference in terms of the SV graft patency rates $(P=0.237)$. The logistic regression model revealed that the independent predictors of the RA graft occlusion were native coronary narrowing $<70 \%$ and female gender (Table 2 ).

\section{Discussion}

Contrasting former studies, which evaluate the RA and SV graft patency in symptomatic patients by angiography $(1,2,11-15)$, this investigation compared the mid-term follow up of the RA and SV patency rate in asymptomatic patients using a noninvasive diagnostic modality-CT coronary angiography. This work discovered that in the asymptomatic patients, the RA conduits had a suitable patency in two to five years. Moreover, although the SV grafts had a relatively higher patency rate than did the RA, the patency rates in the RA and SV grafts were relatively close.
Recent advances in surgical dissection techniques and drug treatment of vasospasm have ushered in renewed attention in the RA as a graft in CABG (15). Numerous observational researches have indicated high patency rate of the RA in comparison with the $\operatorname{SV}(7,10,12)$. Some investigators have shown lower mortality or cardiovascular events in mid-term and long-term follow-up in CABG patients with more arterial conduits in comparison with those grafting by LITA and SV conduits (17). In contrast, others such as Khot et al. (18) and Hortman et al. (2) have reported fewer graft patency rate of the RA when compared to that of the LITA and SV.

In our patients, the graft patency rates were $93.3 \%$ in the LITA, $83.3 \%$ in the RA, and 70.5\% in the SV grafts at two to five years' follow-up. These results are somehow comparable to the findings of other investigators in similar follow-up periods $(12,17,19-22)$. In contrast; Tranbaugh et al. (12) demonstrated that at 10 years postoperative followup, only 50-60\% of the SV grafts were patent. Given that the authors' study population was primarily comprised of patients referring to hospital with cardiovascular symptoms, it is possible to justify the low patency rate of their SV grafts in comparison to that in our study on asymptomatic patients. In our asymptomatic patients, the relatively higher patency rate in the SV grafts and the relatively small sample size precluded us from finding a statistically significant difference between the RA and SV graft patency rates $(P=0.273)$. It is worthy of note, however, that diabetic patients were excluded from our study; the inclusion of such patients might have affected the patency rates to some extent.

Athanasiou et al. (4) and Hata et al. (15) reported that in spite of similar early patency rates, a significant divergence was apparent at extended follow-up period 
between RA and SV grafts. Locker et al. (23) showed that with respect to patency rates, arterial grafts were a better option than were SV grafts at 15 years' follow-up.

We found a significant difference in the RA grafts patency rate in men and women, with a lower rate in females. The same finding was showed by Lawton et al. (24), Schwann et al. (25), and Hortmann et al. (2) due to the minor size of the RA in females.

Conduit management approaches have evolved considerably over the years. Advances in graft-harvesting methods, the use of rigorous statin therapy for precluding atherosclerosis in the SV grafts, and addition of two or more anti-platelet drugs to inhibit the development of thrombus have all played a role in boosting SV patency rates $(15,26)$.

Many researchers have showed RA grafts have a meaningfully greater frequency of decreased flow with higher rates of graft compromise when they are used to graft mild to moderate stenotic target coronary lesions. The patency rate of RA conduits may relay on the preservation of high blood flow, signifying that they must be grafted to the distal segment of severely stenotic target coronary vessels $(1,8,27)$. Cao et al. in a meta-analysis in 2013, concluded that selected patients with severe proximal coronary stenosis may have better patency rates at mid-term follow up after using RA than SV for CABG (28). As a result, in our study, three of five (60\%) patients who had occluded RA grafts on CT-angiography had moderate (50-69\%) stenosis in target vessels.

We obtained reliable and accurate reports of graft conduits patency status by using $2 \times 128$-slice CT angiography. Indeed, multi-detector $\mathrm{CT}$ scanners allow precise analysis of CABG grafts status and are a valuable noninvasive diagnostic modality for mid-term follow-up of patients who underwent CABG including the RA conduits (15).

The present study, conducted on asymptomatic patients, revealed that although there was a relatively higher patency rate in the SV grafts than in the RA grafts, the patency rates in the RA and SV grafts were near to each other. It seems that there was a minor superiority of the RA graft over the SV graft at mid-term CT angiographic follow-up in our asymptomatic patients. Thus, the RA graft function was suboptimal in the patients with several CAD risk factors and in those with less than severe target coronary stenosis and in the females.

Due to financial limitations, we performed the costly CT angiography only on thirty patients free of charge. Thus some of the non-significant results for example that between the RA and SV graft patency rates may be related to this limited sample size. Patency of grafts in CABG is technical dependent in first years. After 10 years the different between vein grafts and LITA graft patency is more significant, and in this study only midterm patency of grafts are evaluated. Also, the decision making of surgeon in CABG is a valuable index for patency of grafts afterward. All surgeons use LITA for left anterior descending coronary artery, the artery that has $55 \%$ of coronary flow of the heart. So, good run off means better patency, all use radial for the best target with up to 80\% proximal occlusion and veins for the rest of targets. This means better patency for former and least for the later. These confounding factors may effect on the studied patency rates.

\section{Authors' Contributions}

Ali Sadeghpour performed CABGs and followed the patients. Hamidreza Pouraliakbar did the CT-angiogeraphy of patients and interprets them. Rasoul Azarfarin did the statistical analysis and wrote the manuscript and contributes in submitting. Alireza Alizadeh Ghavidel was followed the patients and supervised the thesis. Somayeh Zavareian contributed in thesis conduct and paper. Ali Amirahmadi conducted in thesis and contributed and paper and submission.

\section{Funding/Support}

This research was sponsored by Rajaie Cardiovascular, Medical and Research Center, Iran University of Medical Sciences, Tehran, Iran. The hospital covered the cost of CTcoronary angiography of studied patients, so this exam was done free of charge for patients.

\section{References}

1. Collins P, Webb CM, Chong CF, Moat NE, Radial Artery Versus Saphenous Vein Patency Trial I. Radial artery versus saphenous vein patency randomized trial: five-year angiographic follow-up. Circulation. 2008;117(22):2859-64.

2. Hortmann HC, Oliveira HG, Rabello RR, Rocha EA, Oliveira SC Comparison of patency between radial artery and saphenous vein in a coronary artery bypass grafting post operative with return of the symptoms. Rev Bras Cir Cardiovasc. 2010;25(2):218-23.

3. Tranbaugh RF, Dimitrova KR, Friedmann P, Geller CM, Harris LJ, Stelzer P, et al. Radial artery conduits improve long-term survival after coronary artery bypass grafting. Ann Thorac Surg. 2010;90(4):1165-72.

4. Athanasiou T, Saso S, Rao C, Vecht J, Grapsa J, Dunning J, et al. Radial artery versus saphenous vein conduits for coronary artery bypass surgery: forty years of competition--which conduit offers better patency? A systematic review and meta-analysis. Eur J Cardiothorac Surg. 2011;40(1):208-20.

5. Song SW, Sul SY, Lee HJ, Yoo KJ. Comparison of the radial artery and saphenous vein as composite grafts in off-pump coronary artery bypass grafting in elderly patients: a randomized controlled trial. Korean Circ J. 2012;42(2):107-12.

6. Goldman S, Sethi GK, Holman W, Thai H, McFalls E, Ward HB, et al. Radial artery grafts vs saphenous vein grafts in coronary artery bypass surgery: a randomized trial. JAMA. 2011;305(2):167-74.

7. Cao C, Manganas C, Horton M, Bannon P, Munkholm-Larsen S, Ang SC, et al. Angiographic outcomes of radial artery versus saphenous vein in coronary artery bypass graft surgery: a metaanalysis of randomized controlled trials. JThorac Cardiovasc Surg. 2013;146(2):255-61.

8. Yie K, Na CY, Oh SS, Kim JH, Shinn SH, Seo HJ.Angiographic results of the radial artery graft patency according to the degree of native coronary stenosis. Eur J Cardiothorac Surg. 2008;33(3):341-8.

9. Amano A, Hirose H, Takahashi A, Nagano N. Coronary artery bypass grafting using the radial artery: midterm results in a Japanese institute. Ann Thorac Surg. 2001;72(1):120-5.

10. Deb S, Cohen EA, Singh SK, Une D, Laupacis A, Fremes SE, et al. Radial artery and saphenous vein patency more than 5 years after coronary artery bypass surgery: results from RAPS (Radial Artery Patency Study). J Am Coll Cardiol. 2012;60(1):28-35. 
11. Fukui T, Tabata M, Manabe S, Shimokawa T, Takanashi S. Graft selection and one-year patency rates in patients undergoing coronary artery bypass grafting. Ann Thorac Surg. 2010;89(6):1901-5.

12. Tranbaugh RF, Dimitrova KR, Friedmann P, Geller CM, Harris LJ, Stelzer $\mathrm{P}$, et al. Coronary artery bypass grafting using the radial artery: clinical outcomes, patency, and need for reintervention. Circulation. 2012;126(11 Suppl 1):S170-5.

13. Hattler B, Messenger JC, Shroyer AL, Collins JF, Haugen SJ, Garcia JA, et al. Off-Pump coronary artery bypass surgery is associated with worse arterial and saphenous vein graft patency and less effective revascularization: Results from the Veterans Affairs Randomized On/Off Bypass (ROOBY) trial. Circulation. 2012;125(23):2827-35.

14. Possati G, Gaudino M, Prati F, Alessandrini F, Trani C, Glieca F, et al. Long-term results of the radial artery used for myocardial revascularization. Circulation. 2003;108(11):1350-4.

15. Hata M, Yoshitake I, Wakui S, Unosawa S, Kimura H, Hata H, et al. Long-term patency rate for radial artery vs. saphenous vein grafts using same-patient materials. Circ J. 2011;75(6):1373-7.

16. Crusco F, Antoniella A, Papa V, Menzano R, Di Lazzaro D, Di Manici $\mathrm{G}$, et al. Midterm follow-up of patients receiving radial artery as coronary artery bypass grafts using 16-detector-row CT coronary angiography. Radiol Med.2007;112(4):538-49.

17. Habib RH, Schwann TA, Engoren M. Late effects of radial artery versus saphenous vein grafting in patients aged 70 years or older. Ann Thorac Surg. 2012;94(5):1478-84.

18. Khot UN, Friedman DT, Pettersson G, Smedira NG, Li J, Ellis SG. Radial artery bypass grafts have an increased occurrence of angiographically severe stenosis and occlusion compared with left internal mammary arteries and saphenous vein grafts. Circulation. 2004;109(17):2086-91.

19. Tatoulis J, Royse AG, Buxton BF, Fuller JA, Skillington PD, Goldblatt JC, et al. The radial artery in coronary surgery: a 5-year experience--clinical and angiographic results. Ann Thorac Surg. 2002;73(1):143-7.

20. Cohen G, Tamariz MG, Sever JY, Liaghati N, Guru V, Christakis
GT, et al. The radial artery versus the saphenous vein graft in contemporary CABG: a case-matched study. Ann Thorac Surg. 2001;71(1):180-5.

21. Hu X, Zhao Q. Systematic comparison of the effectiveness of radial artery and saphenous vein or right internal thoracic artery coronary bypass grafts in non-left anterior descending coronary arteries. J Zhejiang Univ Sci B. 2011;12(4):273-9.

22. Desai ND, Cohen EA, Naylor CD, Fremes SE, Radial Artery Patency Study I. A randomized comparison of radial-artery and saphenous-vein coronary bypass grafts. $N$ Engl $J$ Med. 2004;351(22):2302-9.

23. Locker C, Schaff HV, Dearani JA, Joyce LD, Park SJ, Burkhart $\mathrm{HM}$, et al. Multiple arterial grafts improve late survival of patients undergoing coronary artery bypass graft surgery: analysis of 8622 patients with multivessel disease. Circulation. 2012;126(9):1023-30.

24. Lawton JS, Barner HB, Bailey MS, Guthrie TJ, Moazami N, Pasque MK, et al. Radial artery grafts in women: utilization and results. Ann Thorac Surg. 2005;80(2):559-63.

25. Schwann TA, Engoren M, Bonnell M, Clancy C, Habib RH. Comparison of late coronary artery bypass graft survival effects of radial artery versus saphenous vein grafting in male and female patients. Ann Thorac Surg. 2012;94(5):1485-91.

26. Dick F, Hristic A, Roost-Krahenbuhl E, Aymard T, Weber A, Tevaearai HT, et al. Persistent sensitivity disorders at the radial artery and saphenous vein graft harvest sites: a neglected side effect of coronary artery bypass grafting procedures. Eur J Cardiothorac Surg. 2011;40(1):221-6.

27. Maniar HS, Sundt TM, Barner HB, Prasad SM, Peterson L, Absi T, et al. Effect of target stenosis and location on radial artery graft patency. J Thorac Cardiovasc Surg. 2002;123(1):45-52.

28. Cao C, Ang SC, Wolak K, Peeceeyen S, Bannon P, Yan TD. A metaanalysis of randomized controlled trials on mid-term angiographic outcomes for radial artery versus saphenous vein in coronary artery bypass graft surgery. Ann Cardiothorac Surg. 2013;2(4):401-7. 